\title{
Cinematic Perspectives On Organizational Mentoring
}

David P. Boyd, Northeastern University, USA

\begin{abstract}
Properly conceived and conducted, organizational mentoring can bestow benefits on the suppliant, the mentor and the firm. If prospective protégés assess the context of a mentoring relationship before they enter into one, they can enjoy a bonding experience that facilitates psychological satisfaction and furthers professional advancement. The movie medium is an educative means of appreciating and attaining these positive outcomes. The instructive lens of drama can complement traditional curricular materials in courses on behavioral dynamics. Over the past seven years, the author has assigned a film project in his Leadership classes at the undergraduate and MBA level. Of the 120 films chosen for students projects, five compellingly capture functional and dysfunctional aspects of protégé-protector linkages. After analyzing these films, the paper proposes ten precepts that will enhance the mentoring experience for workplace aspirants.
\end{abstract}

Keywords: Curriculum, Films, Mentoring

\section{INTRODUCTION}

hether of a formal or informal cast, mentoring is touted as a productive panacea for the workplace.
As role models in relationally based dyads, mentors can enhance the careers of their charges.
Specifically, they can provide both strategic direction and skills development. These instrumental and social functions are inextricably linked. Mentees who can facilitate interaction are likely to fulfill objectives. Each win increases the probability of success and satisfaction from the next exchange (Baker, 1994). By serving as gatekeeper, a sponsor can continually position the protégé to access resources inside the organization and even beyond it (Eby 1997; Eby et al., 2000). Moreover, the benefits of mentoring are bilateral. Sponsors as well can reap the rewards of intrinsic satisfaction. They can become co-learners along with their protégés (Kram \& Hall, 1996). Sponsors can secure information from below and glean feedback on the viability of managerial initiatives (Gilkey \& Kilts, 2007; Mullen, 1994).

The benefits that accrue from mentoring extend beyond the dyadic relationship. Mentoring can foster a sense of employee commitment to the organization. When initiated during recruitment, mentoring represents an effective means of socialization (Payne \& Hufman, 2005). Not surprisingly, it has been shown to augment retention (Lankau \& Scandura, 2002). Under such circumstances entrants are prone to assimilate core values, thereby furthering ties to cultural tenets (Viator \& Scandura, 1991). Organizations can thereby develop a talent bench of future leaders.

Of course, mentoring should not be construed as the sole source of personal learning. Mentees should always be attentive to larger networks. Protégés should be counseled to avoid over-reliance on sponsors for career and psychosocial guidance. They should remain cognizant of chance encounters; telling tidbits can be gleaned at the water cooler or the cafeteria table. Moreover, while mentoring can optimally abet mentor, mentee and organization, pitfalls abound. For example, Scandura (1998) provides a theoretical map of dysfunctional mentoring relationships. Since sponsors implicitly wield greater relative power, they can exercise that influence for personal ends, thereby abusing and abrogating the relationship (Ashforth, 1994). 
Particular situations require caution. Mentors with protégés of the opposite gender can realize productive outcomes from the relationship. Some research suggests that positive results might be more likely in such instances because each party is aware of the potential for distraction or disruption (Noe, 1988). Nonetheless, in order to enjoy success, at the first meeting expectations have to be clarified and any problems resolved. The call of home commitments can represent another impediment to female career ascension (Eagly \& Carli, 2007). For this reason mentoring mechanisms may hold special value for women.

Finally, it should be remembered that even good things draw to a natural end. The mentoring experience is characterized by well-delineated sequential stages. After the phases of initiation and cultivation, scholars have discerned a proclivity for natural separation. This division occurs typically between two and five years, resulting in a redefinition of the original psychological contract (Chao, 1997; Kram, 1985). Mentees and their mentors should stay mindful of these temporal parameters so that distance does not cause diviseness. Though relationships may be front-loaded with fulfillment, the gleam can be transient. Protégés should be ready to disengage before neglect and frustration take their toll (Eby et al).

The question guiding this study is straightforward. Relationship-based mentoring can be fruitful for the parties involved. If so, the host organization becomes the ultimate beneficiary. Yet behavioral guidelines must be followed to ensure organizations realize these potential benefits. By drawing on the medium of film, this paper will propose principles that make mentoring safe and successful.

\section{DRAMATIC DEPICTIONS OF ORGANIZATIONAL MENTORING}

Since the 1970s business school educators have used film as a teaching tool (Champoux, 1999). Film exposes a classroom audience to intention as well as consequence. It is thus a suitable vehicle for both predictive speculation and retrospective commentary. In the words of Michaelson et al. (2006), viewers can analyze character depiction "from the vantage point of relative omniscience" (p. 4). Films can complement the written materials customarily employed in organizational behavior and leadership courses.

Narrative fiction, including its filmic form, can offer perspective on how organizations work (Boje, 1995). Movies can elucidate the behavioral dynamics that exist in organizational settings, including those beyond the purview of the actual film. Compared to the free flow that permeates the corridors of real organizations, the movie medium allows pivotal events to be frozen in time, thereby rendering them susceptible to didactic review. Through the hypothetical depictions of film, viewers can extrapolate real world takeaways. Movies can be more than seductive escape from organizational life; they can be a source of sustenance and success within that very workplace.

Moreover, much like selected chapters from a larger tome, discrete scenes allow focus on subtle but strategic strands within the larger social setting. Cinematic vignettes allow the viewer to scrutinize the subtext that builds toward narrative denouement.

\section{SHAWSHANK REDEMPTION}

\section{Plot Summary}

Andy Dufresne is a young banker who is sent to Shawshank Prison for the murder of his wife. There he is taken under wing by long incarcerated Ellis Redding who goes by the sobriquet of "Red." Over time Andy gains influence throughout the institution so the mentor and mentee reverse roles.

\section{Mentoring Roles}

Although set in a context alien to most, the movie provides perspective on the conduct of professional life. As a seasoned insider at Shawshank Prison, Red wields influence among the population and has elicited the trust of his peers. Known as the prison entrepreneur who is proficient at procurement, he secures a rock hammer so Andy can pursue his avocation of rock collecting. Red has a kind bent and senses that Andy will wilt without the 
protective panoply of a mentor. Red does not yet recognize Andy's peculiar brand of fortitude. Though strong of character, Andy's toughness is at first difficult to discern. Inmates and guards mistake his equanimity for vulnerability. Red surmises that Andy will be the first of the new prisoners to fold under Shawshank's cold cruelty.

Ever the alert opportunist, Andy accrues status by making others dependent on him. Using his accounting expertise, he assists guards with tax questions. The acquisition of mentee power often advances through a ripple effect. Observing Andy's way with their captain, the other guards queue with queries. Andy's capabilities are also noted by inmates. These social perceptions generate momentum that Andy can leverage. In exchange for his services, Andy requests that the men be given beer - even though he does not consume liquor himself. Altruism appears to drive his strategy and the fruits of his bargaining are enjoyed by all. He seeks no recognition for his deeds; he revels in the spectacle of his friends' conviviality.

As Andy expands his epicenter of influence, he invariably changes the mentor-mentee roles. Relationship based on demarcation moves to partnership characterized by co-leadership. For his part Red seems comfortable dispersing power to his protégé. He exhibits no envy and no recalcitrance about relinquishing his role. The transition continues until it culminates in transformation. Red in the end becomes Andy's right-hand man. Red has not really lost influence within the prison cohort; rather Andy has gained it.

Why does this dyadic reversal inevitably occur? Red is inclined to exercise influence subtly within the acceptable bounds of prison norms. Red's persona or process never smacks of the outlandish. By contrast, Andy is inspirational and charismatically displays extraordinary behavior. He flouts institutional tenets and even plays music over the loud speaker. Because Andy is an integrative negotiator, his counter-cultural symbolism does not invite retaliation. He understands what other people need and he knows how to satisfy those needs. He builds relationships not only with the prison population but with those who hold formal authority over them, including the prison board. Andy casts a wide net, cultivating those around and above him. He tutors inmates to facilitate their quest for a high-school diploma. His dogged pursuit of a library comes to fruition. Now inmates can scope the world outside before they step into it. The library stands as a tangible testament to future possibilities. Andy knows that he will no longer be among these men. Yet he will not escape until he has left this legacy. He has pushed the ball forward and now the team will take over in his absence.

The film demonstrates how the balance of power can alter over time within the mentor-protégé dyad. Each member influences the other with his knowledge and his particular brand of referent power. Yet Andy's actions are more profoundly pervasive. Though he remains beside Red, he moves beyond him and mentors the whole prison population. His social skills trump the fact that he is really the odd- man-out in terms of prisoner profile. He is lucid in discussion and educated in his craft. Surprisingly, such differentiation earns him regard rather than resentment.

\section{Mentoring Rules}

1. When mentors are willing to share power, both mentor and mentee accrue even more.

2. Mentees can expand influence by creating situations where others depend on them.

\section{NORMA RAE}

\section{Plot Summary}

Norma Rae toils in a textile plant, the major employer in her rural town. Her workdays are devoid of meaning until she meets a professional labor organizer. Together they embark on a quest to unionize the factory, in the process confronting a management all too willing to tolerate the intolerable working conditions.

\section{Mentoring Roles}

Reacting against management that is both distant and adversarial, Norma Rae becomes an agent of change and a beacon of hope for her fellow workers. She is a role model who galvanizes them into action. Yet she 
shrewdly realizes that she cannot single-handedly jettison the status quo conditions at the mill. She must work in concert with a mentor, in this case a smart and smooth labor organizer from New York.

Reuben, her urban and urbane counselor, schools her in the way of emotional intelligence. He encourages her to exert self-control and show sensitivity toward the feelings of others. Through this kind of participative style, Reuben explains that she can engender a sense of constituent ownership. With his education and experience, he knows that she can better engage her colleagues through responsible delegation rather than repressive demands.

Sensing a threat in Norma, her bosses promote her into the management ranks. Their intent is not merely to co-opt her but to diminish her perceived commonality with her former co-workers. Reuben continues to counsel her on the importance of high relationship as well as high task. He espouses two-way communication and socioemotional support to ensure that others follow her lead. Yet once ensconced in her new position, she does not do so - and perhaps cannot given the monolithic mentality that grips her managerial peers. She inexorably becomes an extension of the reviled regime and so forfeits credibility on the assembly line. With Machiavellian intent the mill boss has eroded her standing even as he has elevated her status. Her leader position now constrains her leader performance. Recognizing that she must forego title in to order to find solidarity on the floor, she resigns her post. At last truly mindful of her mentor's advice, she sheds her penchant for clamorous dissonance whether directed toward managers or workers. Instead she opts for silent symbolism as she perches on a table brandishing a placard that reads simply "union."

In fairness, it should also be noted that Norma advises Reuben. She implants some sense of street smarts in this charismatic cosmopolitan. She shows him how to speak to the workers in their language. When sponsors journey down the mountain, they must converse in the dialect of the village.

\section{Mentoring Rules}

3. Mentors must align their methods and message with their targeted audience.

4. Mentees can often augment their influence through pull rather than push.

\section{GOOD WILL HUNTING}

\section{Plot Summary}

The film tells the story of an unschooled mathematical genius hapless at leveraging his intellectual prowess and helpless at lightening his emotional load. To the rescue come a celebrated professor and a cast-off psychiatrist. However, they offer the young whiz different and divergent ways out of his dilemma.

\section{Mentoring Roles}

Will's roughly hewn manner belies an untapped reservoir of raw intellect. As his vast potential becomes apparent to others, he finds himself in the unique position of having two mentors. Yet multiple mentors lead to multiple problems and Will must break away from one of his sponsors.

The renowned MIT Professor Gerald Lambeau leverages positional power while the less ostensibly successful psychiatrist Sean Maguire exercises personal power. One wields a key to professional growth while the other waves a wand to personal growth. In this race to connect, Maguire emerges the victor. Genius though he may be, Will does not espouse the academic trappings that surround Lambeau's mathematical triumphs. Only through legal mandate and institutional coercion can Lambeau induce Will to attend tutoring sessions. Will has the ability to engage in intellectual discourse but lacks any aspiration to do so.

Maguire's tutelage, by contrast, relies on persuasion. Replete with emotional intelligence, he can discern the root of Will's angst. Having himself suffered abuse in his early years, Sean can recognize Will's demons and help expurgate them. Maguire senses the emotional overhang of his young charge. He unmasks himself before his patient, proving that he is full of both heart and hurt. Sean has suffered the slings of fortune and now sees his 
protégé with no harbinger of hope. Focusing on Will's psychological comfort, he can forge a pathway to emotional enlightenment. By contrast Lambeau appears intent on basking in the halo of a developing wunderkind. Lambeau is propelled by the lofty notion of serving his profession and the personal gratification of grooming genius. Maguire opts for pull rather than push. While Lambeau can guarantee freedom from the law, Maguire can grant freedom from the weight of self. In this contest, formal authority proves vacuous. Lambeau may have the right to postulate formulas but Maguire has the ability to probe feelings.

Will's mentors entertain variant definitions of success. Because his sponsors fail to coordinate their protocol for Will, only one of them can hold sway. Lambeau wants Will to get the job; Maguire wants him to get the girl. While protégés might presumably expand their sphere of influence through multiple sponsors, synergy does not automatically arise from such a situation.

\section{Mentoring Rules}

5. Successful mentors are humble teachers who shun a "follow me" mentality.

6. Mentees should seek a sponsor whose goals are consonant with their own.

\section{WALL STREET}

\section{Plot Summary}

Without heed to others, and without any apparent need for them, Gordon Gekko has amassed a fortune on Wall Street. A young ambitious broker falls under the spell of this tour de force manipulator. Yet the mentor's selfcenteredness dooms the relationship.

\section{Mentoring Roles}

Tired of penury, Bud Fox longs to cruise the fast lane. He sets his sights on Gordon Gekko, a stock speculator on the cover of Fortune Magazine. Gekko brims with confidence and his words carry a resolute ring. Bud is captivated by Gekko's persona and energized by his presence. The young aspirant seeks Gordon's approval, and emulation is his means of doing so. Recognition from this celebrated predator will gratify Bud's need for achievement as well as his desire for acceptance.

Gordon agrees to groom the protégé because he senses fertile soil for tilling. He confesses to Bud "you remind me of myself," and the conversion cycle commences. Gekko is a daring and deft militarist who shows Bud how to extract information. Quoting Sun Tzu, Gekko avers that "every battle is won before it is ever fought." Gordon jettisons all regard for reciprocal empathy and runs his whole life like a calculated campaign. He shares his humble origins and then showcases his Herculean strides to move beyond them. He assures Fox that there is always room on the highway for those with the resolve to speed by others.

Evidence of successful shaping occurs when Bud later quotes another Tzu precept. Fox is adopting the behavior of his mentor and assimilating the attitudes that underpin such behavior. The cunning sponsor molds his malleable charge and then rewards him for displays of compliance. Conformity begets autonomy; the relationship becomes increasingly characterized by parity and collegiality. Seemingly safe and secure within the inner sanctum of Gekko's corporate family, Bud feels both valuable and valued. This professional partnership supersedes all ties to Fox's paternal mentor. Yet this very insularity sets the stage for downfall.

Made pompous by prosperity, Gekko suffers from an illusion of invulnerability. Secretly conniving to dismantle the airline where Bud's father works, Gekko fails to see that encroachment on the livelihood of a father could become a boundary situation for the son. Gordon is oblivious to the sway of family allegiance. Because he eschews emotion himself, he fails to recognize it in others. When mentors lose the trust of their protégés, they lose capacity to influence them. Had Gekko taken the time to analyze the situation from Fox's perspective, he could have better protected himself. Bud retaliates, allying with one of Gordon's arch foes who purchases the airline for 
the sheer delight of thwarting his rival. Now versed in Wall Street subterfuge, Bud manipulates the airline's stock price so that Gekko incurs a massive loss.

Bud has finally realized that "Gekko the Great" is not so great after all. He cannot be like him nor does he wish to be. Adrift in a moral abyss, he resolves to resurrect his true character. Yet this final epiphany is characterized by revenge as much as by redemption. While he rejects Gekko's value set, Bud deploys cutthroat tactics that he has gleaned under Gordon's tutelage. The lessons transmitted by the mentor are now turned against him. Bud reclaims the moral high ground only after he has consummated his vendetta.

\section{Mentoring Rules}

7. If mentors exploit their protégés, their protégés may try to exploit them.

8. Mentees should seek sponsors who complement expertise with empathy.

\section{ONE FLEW OVER THE CUCKOO'S NEST}

\section{Plot Summary}

Randall McMurphy, a newly committed patient in a 1950s mental hospital, resolves to liberate his fellow inmates from the institutional routines that humble and humiliate them. Over time he coaxes them toward enjoyment and esteem. Under Mac's mentorship they laugh and learn. However, Mac's arch nemesis Nurse Ratched opposes Mac's rowdy and rebellious ways.

\section{Mentoring Roles}

Undeterred by institutional rules, Mac is a charismatic change agent who can distill complex ideas into simple messages. Confronted by patients who are challenged in cognition and spatially confined, he dons the mantle of mentorship for all potential protégés. To forge relationships he uses grassroots leadership, flouting standard operating procedures and relentlessly questioning the rationale for them. He is a Johnny Appleseed mentor, planting seeds of change wherever he finds a listener. Drawing on his expertise in games and gaming, he empowers the inmates through instructive example.

Mac induces a Pygmalion Effect and inspires some of his more cogent colleagues to become what they truly yearn to be. They shed their "loony" label, exhibiting bravado on the basketball court and becoming facile fishermen. The issue is neither the grand total of baskets scored nor the final tally of fish landed. A single shot is cheered as victory in its own right. This strategy of small wins generates forward momentum, creating confidence and commitment to achieve more. Even failure is acceptable as in Mac's doomed attempt to budge the water cooler. According to Mac, failure simply means unwillingness to try. The other patients like Mac and therefore want to be like him. This emulation increases his capacity to influence. Ward members continually await his intentions and absorb his instructions.

Yet Mac has failed to institutionalize his radical approach. He has formed a coalition of patients but not a coalition of professionals. Even though he faced adversaries, he never sought allies. He did not garner the support of doctors on the staff nor did he deploy his persuasive powers to show administrators why his actions were beneficial for patients. He failed to articulate and leverage the small successes the men enjoyed under his tutelage. Invariably, then, he is flummoxed in his quest to effect a cultural shift. Though McMurphy has established a mentoring relationship with many of the patients, Nurse Ratched will never permit him to formalize this role. The more her positional power is challenged, the greater her fervor in hoarding it. Any skills development among her charges might usurp her unilateral ways. Mac is part of a system where change is construed as threat. The prevalent sentiment is to foster learned helplessness among inhabitants of the wing.

Thus Mac's antics inexorably build to a tragic denouement for himself and for those around him. Mac's liveliness is eviscerated by a lobotomy. The men continue in a system that circumscribes their thoughts and actions. Nor, sadly, can they function outside these boundaries. Mac's charges are not equipped to embrace his brand of 
rampant expressionism. Billy commits suicide after his dalliance with a prostitute. The flight of the chief will be short-lived; he will soon be reclaimed by the ward with his wings clipped.

While an energized and energizing symbol, Mac will not remain an enduring one. All his fanfare will prove futile and his influence fleeting. Perpetuity is the true measure of mentor success. Mac's legacy dies with him.

\section{Mentoring Rules}

9. Mentors' persuasive power must be legitimated by organizational context.

10. Mentees should consider whether sponsor advice remains tenable if their protector is no longer present.

\section{CONCLUSION}

This paper has examined mentoring relationships from the perspective of both mentor and mentee. Through the medium of film, mentees can learn how to manage their mentors. Mentors can learn how to provide their protégés with social as well as instrumental support.

Collectively, the five films depict mentoring's temporal progression; the dyadic bond evolves from an emergent to an established phase and finally to an end. In the beginning, prospective mentees should take an introspective inventory of life lessons already imparted. They can then scour for a mentor whose abilities and attributes align with their needs, as is the case in Good Will Hunting. Mentees need to expose their expertise and not assume that others are already aware of it. For their part mentors should shun a myopic mindset and frame precepts within the context of the corporate culture, a point illustrated in One Flew over the Cuckoo's Nest.

Once a mentoring relationship has been established, bilateral benefit should be the cornerstone of engagement. As pro bono advisors mentors do not exact payment in currency. Mentors, though, deserve recognition and respect for their efforts. Mentees must observe the norm of reciprocity even if their only way of so doing is emotional acknowledgment. The perspectives of each party should be integrated for mutual advantage, as occurs in Norma Rae.

Relationships do and should end. How they end is pivotal in the eyes of others. In Shawshank Redemption the protégé surpasses his protector yet the reconfiguration takes place without hostility or hubris. By contrast, in Wall Street the protégé spurns his mentor, and the public sparring rings with the discord of divorce. Outsiders will cast the pall of failure over the entire history of the relationship, remembering only that it was dismantled. Cessation should always ensue from a sense of tasks compatibly completed.

Films such as the ones profiled in this paper show the rewards to be gained and the roadblocks to be dodged in mentoring relationships. A movie milieu can guide viewers in forestalling failure and also in foreshadowing success. By analyzing the actions of others in film, potential protégés can become more adept actors in their own life situation. Mentoring in movies can help accelerate an aspirant's career; it can also help align a professional career with one's personal life.

\section{AUTHOR BIOGRAPHY}

David P. Boyd is Professor of Human Resources in Northeastern University's College of Business Administration where he served as dean from 1987 to 1994 . Professor Boyd has published over fifty articles in the area of organizational psychology and entrepreneurial behavior. His work has appeared in such journals as the Harvard Business Review and the Sloan Management Review. He holds a BA from Harvard University and a D.Phil. from Oxford University, England.

\section{REFERENCES}

1. Ashforth, B. (1994). "Petty Tyranny in Organizations," Human Relations, 47: 755-778. 
2. Baker, W. E. (1994). Networking Smart: How to Build Relationships for Personal and Organizational Success. New York: McGraw-Hill.

3. Boje, D. M. (1995). "Stories of the Storytelling Organization: A Postmodern Analysis of Disney as Tamara-Land," Academy of Management Journal, 38: 997-1035.

4. Champoux, J. E. (1999). "Film as a Teaching Resource," Journal of Management Inquiry, 8: $206-217$.

5. Chao, G. T. (1997). "Mentoring Phases and Outcomes," Journal of Vocational Behavior, 51: 15-28.

6. Eagly, A. H. \& Carli, L. L. (2007). "Women and the Labyrinth of Leadership," Harvard Business Review, 85: 63-71.

7. Eby, L. T. (1997). “Alternative Forms in Changing Organizational Environments: A Conceptual Extension of the Mentoring Literature," Journal of Vocational Behavior, 51: 124-144.

8. $\quad$ Eby, L. T., McManus, S. E., Simon, A. A., \& Russell, J. E. A. (2000). “The Protégé's Perspective Regarding Negative Mentoring Experiences: The Development of a Taxonomy," Journal of Vocational Behavior, 57: 1-21.

9. Gilkey, R. \& Kilts, C. (2007). “Cognitive Fitness,” Harvard Business Review, 85: 53-66.

10. Kram, K. E. (1985). Mentoring at Work. Glenview, IL: Scott, Foresman.

11. Kram, K. E. \& Hall, D. T. (1996). "Mentoring in a Context of Diversity and Turbulence.” In E. Kossek \& S. Lobel (Eds.), Managing Diversity: Human Resource Strategies for Transforming the Workplace: 108136. Cambridge, MA: Blackwell.

12. Lankau, M. J. \& Scandura, T. A. (2002). “An Investigation of Personal Learning in Mentoring Relationships: Content, Antecedents, and Consequences," Academy of Management Journal, 45: 779-790.

13. Michaelson, C., Gerde, V., Goldsby, M. G., Orlitzky, M., \& Schoepner, C. (2006). "Bringing the Power of Film to Business Ethics Research and Teaching," Academy of Management Annual Meeting Panel Symposium: 1-14.

14. Mullen, E. C. (1994). Mentorship Revisited: Viewing the Protégé as a Source of Information for the Mentor. Unpublished doctoral dissertation, University of Minnesota.

15. Noe, R. A. (1988). "An Investigation of the Determinants of Successful Assigned Mentoring Relationships," Personnel Psychology, 41: 457-479.

16. Payne, S. C. \& Huffman, A. H. (2005). "A Longitudinal Examination of the Influence of Mentoring on Organizational Commitment and Turnover,” Academy of Management Journal, 48: 158-168.

17. Scandura, T. A. (1998). "Dysfunctional Mentoring Relationships and Outcomes," Journal of Management, 24: 449-467.

18. Viator, R. E. \& Scandura, T. A. (1991). "A Study of Mentor-Protégé Relationships in Large Public Accounting Firms," Accounting Horizons, 5: 20-30. 